\title{
Parentesco y localidad. Un grupo gitano transnacional
}

\author{
Budilová Lenka y Jakoubek Marek \\ Universidad de Bohemia \\ budilova@ksa.zcu.cz,jakoubek@ksa.zcu.cz
}

Resumen: La caída del comunismo en la Europa central y oriental y la emergencia de dos estados independientes - la República Checa y la República Eslovaca - llevó consigo una variedad de cambios en la percepción de la identidad de los habitantes de ambos estados. Con la división de la antigua Checoslovaquia, se formaron nuevas fronteras que no influyeron de manera intensa en la percepción de la identidad del grupo de algunos grupos roma/gitanos en los países en cuestión. El proceso de integración de la Unión Europea durante los últimos años llevó consigo nuevas oportunidades: el movimiento de población, las oportunidades laborales y una movilidad laboral más intensa. En el texto vamos a discutir el problema de la identidad en un grupo roma/gitano $y$ el efecto aparecido durante los últimos veinte años relativo a su propia percepción sobre quiénes son. En este texto abordamos los principales temas de nuestra investigación sobre la identidad: la identidad local, la identidad relativa al Estado, la identidad europea y la identidad roma transnacional. Discutiremos sobre la relación mutua entre diversos estratos de las identidades y la medida en que estas relaciones se muestran influidas por el proceso contemporáneo de la integración de la Unión Europea.

Palabras clave: Checoslovaquia; identidad; migración; parentesco; roma/gitanos.

Abstract: The fall of communism in Central and Eastern Europe and the emergence of two independent states - the Czech and the Slovak Republic - brought wide-ranging changes in the perception of the identity of the inhabitants of these states. The division of the former Czechoslovakia established new borders, which, nevertheless, did not have any big effects on either the migratory movements between the newly founded states or the perception of the group identity of some of the Roma/Gypsy groups in 
respective countries. The EU integration process in recent years has given rise to new opportunities - movements of people, job opportunities and more intensive labour migrations. In this text we discuss the identity problem of a Roma/Gypsy group and the effect that the social and political changes that have emerged in the last 20 years have had on their perception of who they are. In particular, our investigation focuses on questions of identity (local identity, kinship identity, state identity, European identity and the trans-national Roma identity). We will discuss relationships between various strata of identities and the extent to which these relationships are influenced by the contemporary processes of EU integration.

Keywords: Czechoslovakia; identity; kinship; locality; migration; Roma/ Gypsies

\section{Prólogo}

En los textos relacionados con el tema del transnacionalismo, los roma/gitanos figuran típicamente como una diáspora — véase, por ejemplo, Armstrong (1976: 393), Safran $(1991$ : 87, 96) y Sheffer $(1995: 23-25,26)$ - . En los textos correspondientes, los roma/gitanos son tratados al unísono como un grupo o una comunidad. El fundamento de la pertenencia a la comunidad y el rasgo constituyente de la comunidad lo representa la etnicidad o la nacionalidad común, que es igualmente considerada como elemento clave en el conjunto de las identidades colectivas de los participantes en cuestión. Los textos especializados trabajan con el tema de la diáspora roma/gitana generalmente en el contexto de la Europa occidental o del conjunto de Europa, o incluso en el contexto mundial, entonces a un nivel relativamente amplio, un macronivel. Esta situación conduce a la argumentación correspondiente, que se sitúa relativamente lejos de la actuación real de los miembros de la diáspora respectiva. El objetivo de las páginas siguientes no será entrar en una polémica directa con los textos respectivos ni con el modo de reflexión sobre los roma/gitanos. En vez de proceder de esta manera, presentaremos una descripción de la actuación transnacional de los actores roma/gitanos, que serán contemplados desde el punto de vista de una perspectiva antropológica alternativa próxima a la experiencia. La unidad dentro de la que contemplaremos la reproducción de las relaciones transnacionales no será un grupo étnico roma/gitano o una diáspora 
roma, sino un grupo concreto roma/gitano unido por los vínculos del parentesco. El contexto de nuestra descripción se sitúa en la antigua Checoslovaquia y en sus estados sucesores, por lo tanto, en las repúblicas checa y eslovaca en el periodo a partir del final de la Segunda Guerra Mundial.

Con el ejemplo de un grupo roma/gitano que vive en el territorio de las repúblicas checa y eslovaca demostraremos, en el texto siguiente, de qué manera influyó la eliminación o el nuevo establecimiento de las fronteras entre los dos estados durante los últimos sesenta años sobre el carácter del grupo y sobre la identidad de sus miembros. El foco de nuestro interés se centrará en el tema de las relaciones de parentesco y la migración que, como demostraremos, tuvieron un impacto fundamental en la formación de la identidad de los miembros del grupo observado. El problema de la migración y del parentesco será analizado desde una perspectiva dinámica. Nos interesaremos por las transformaciones del grupo observado que ocurrieron durante varias décadas anteriores. Examinaremos la influencia mutua de la migración y de las relaciones de parentesco y demostraremos qué consecuencias pueden tener nuestras conclusiones en el concepto de las comunidades roma en las repúblicas checa y eslovaca. Los datos analizados en este texto representan un resultado de la investigación sobre el terreno realizada en los años 2000-2013 en las aldeas roma/gitanas eslovacas ${ }^{1}$ y en los guetos checos de los roma/gitanos en los suburbios municipales o en las localidades socialmente excluidas.

\section{Introducción. Contexto histórico}

Las repúblicas checa y eslovaca, es decir, la antigua Checoslovaquia, han mostrado una gran cantidad de movimientos migratorios importantes de poblaciones roma/gitanas durante el siglo xx. El hecho más importante es que los grupos roma/gitanos que viven actualmente en la República Checa son grupos totalmente diferentes de los que habían vivido en este territorio antes de la Segunda Guerra Mundial (Lípa, 1965: 5-9). Los roma/gitanos que viven actualmente en la República Checa son casi totalmente descendientes de los que se movieron desde Eslovaquia después de la Segunda Guerra Mundial. Antes de la guerra, los grupos de gitanos/roma checos y moravos vivieron en el territorio que es hoy la República Checa (véase, por ejemplo, Hanzal, 2004).

1 Para la definición del concepto cigánská osada (aldea gitana), véase Budilová-Jakoubek (2005b). 
La mayor parte de ellos no sobrevivieron a la guerra; solamente unas centenas de las personas de estos grupos vivieron en el territorio de la que hoy es la República Checa después del año 1945. A esta época triste de la historia checa se le ha dedicado mucha atención en los últimos decenios y es la época que constituye el capítulo más estudiado de la historia de los roma/gitanos checos y moravos (Nečas, 1981: 84-103; Nečas, 1999: 66-83; Nečas, 2000; Lípa, 1990; Pape, 1997; Van Baar, 2008). De los varios miles de personas que vivían antes de la Segunda Guerra Mundial en el territorio de la República Checa actual, sobrevivieron apenas un par de cientos de personas (Haišman, 1993; Nečas, 1999: 83).

En la posguerra, las regiones fronterizas de la República Checa actual (el Sudetenland, en alemán, o los Sudety, en checo), las regiones limítrofes septentrionales y occidentales de la República Checa, mostraron grandes migraciones. Estas áreas fueron habitadas antes de la Segunda Guerra Mundial en gran parte por los alemanes, y ciertas ciudades de las regiones eran incluso puramente alemanas. Como consecuencia, había áreas despobladas y casas y ciudades deshabitadas (Staněk, 1991; Brandes, 2001). En los años de la posguerra estas regiones se iban poblando, en primer lugar, espontáneamente, $y$, más tarde, de una manera organizada por diversos grupos de personas. Entre estos estaban los checos del interior, diversos grupos de compatriotas checos de Bulgaria, de Rumania, de Yugoslavia (Nosková y Váchalová, 2000; Vaculík, 1993) y de Ucrania (Vaculík, 1984), entre otros. Entre los recién llegados estaban también los roma/gitanos de Eslovaquia. Inicialmente, los roma/gitanos llegaron espontáneamente, algunos de ellos en respuesta a la difícil situación en los asentamientos roma/gitanos en algunas regiones de Eslovaquia del Este tras el final de la guerra. Algunos asentamientos estaban fuera del alcance de los caminos y los pueblos durante la guerra, algunos de ellos incluso fueron destruidos; además, la situación económica era mala, los índices de desempleo eran altos, etc. (Hübschmannová, 2006; Vagačová y Fotta, 2006) y los roma/ gitanos no pudieron volver a su domicilio después de la guerra, ya que este ya no existía. Esta gente buscó mejores condiciones de vida para sus familias en la República Checa (Pavelč́ková, 2004: 25-30).

Estas migraciones fueron incentivadas más adelante por el gobierno: ofrecieron a los roma/gitanos de Eslovaquia casas y trabajo en algunas regiones de Bohemia septentrional y occidental y de Moravia septentrional. Como reacción 
a la Directiva del Comité Central del Partido Comunista Checo del año 1962 sobre la eliminación de los asentamientos roma/gitanos en Eslovaquia, se fundó en 1965 el Comité del Gobierno sobre las Cuestiones de los Habitantes Gitanos, que empezó a realizar su programa llamado Instrucciones de cómo organizar la dispersión y el desalojo, y lo puso en práctica en diciembre de 1965, según la Decisión del Gobierno n. 502/1965 (Krištof, 2003: 9; Nečas, 1999: 103). El objetivo del programa fue desalojar a los roma/gitanos desde diversas partes de Eslovaquia donde vivían más concentrados hacia las zonas industriales checas para asimilarlos más fácilmente en la sociedad de los alrededores (Nečas, 1999: 103; Davidová, 2000: 74). Se estableció un sistema de «departamentos hermanados», así que los roma/gitanos de un departamento concreto de Eslovaquia se trasladaban a un departamento concreto en Bohemia. El gobierno dirigió a la gente que llegó en esta oleada migratoria principalmente al Sudetenland donde, además de los nuevos habitantes, era necesario suministrar una nueva mano de obra para fábricas y granjas cooperativas recientemente construidas. En Eslovaquia, a estos migrantes se les pagaba cierta cantidad de dinero que podían cobrar solo en una ciudad designada en Bohemia y tenían que utilizar el dinero, por lo tanto, para comprar una casa o un piso y para conseguir trabajo. ${ }^{2}$ Todos pertenecían a los grupos de gitanos eslovacos y húngaros cuyos antepasados vivían en el territorio de Eslovaquia de una manera sedentaria en la parte de habla eslovaca o húngara desde hace varios siglos (Mann, 2001). Hablaban uno de los dialectos de la lengua romaní eslovaca (Lípa, 1965). En la mayoría de los casos se trataba de grupos muy distintos de los roma/gitanos checos y moravos de anteguerra y también de los roma/gitanos del grupo Olach, ${ }^{3}$ que se estiman en un $10 \%$ de la población actual de los roma/gitanos en la República Checa (Horváthová, 2002: 63).

\footnotetext{
2 Este esquema de trasvase forzado llegó a ser uno de los temas del documento de la Carta 77, Sobre la situación de los roma/gitanos en Checoslovaquia, que fue publicado en forma de samizdat bajo el n. 23 el día 13 de diciembre de 1978 y fue firmado por los portavoces de la Carta 77: Vaclav Havel y Ladislav Hejdánek (Šiklová, 2002, Krištof, 2003: 9).

3 Los roma/gitanos del grupo Olach son los descendientes de los grupos gitanos que desde finales del siglo xIx empezaron a migrar hacia el Oeste y a instalarse en la Europa central y occidental (y más tarde en los EE. $\mathrm{UU}$ ). De los roma/gitanos ya asentados, que forman la mayoría de la población actual de los roma/gitanos en la República Checa y Eslovaca, se distinguían por ser grupos nómadas en su mayoría hasta el año 1959, cuando fueron asentados de una manera forzada. Además, se distinguen por su dialecto del romaní, por su aspecto físico, por la alimentación, por varios rasgos folclóricos y por los rasgos culturales generales (más sobre este grupo: Stojka y Pivoň, 2003).
} 
La última oleada migratoria de los grupos roma/gitanos de Eslovaquia a la República Checa ocurrió después de 1989. La migración continuó en los años noventa del siglo pasado. Como la República Federal Checa y Eslovaca fue dividida en 1993 y se formó la frontera entre dos estados nuevamente establecidos — la República Checa y la República Eslovaca-, la migración después de esta fecha ya no era un movimiento dentro de un Estado, sino a través de la nueva frontera. A diferencia de los dos movimientos precedentes, esta oleada migratoria no era tan masiva como las dos oleadas precedentes: la de posguerra y la de los años setenta del siglo pasado. Durante las dos primeras oleadas migratorias, los grupos roma/gitanos se establecieron en Bohemia, y, en la última oleada, los grupos roma/gitanos ya estaban viviendo en las ciudades checas desde hacía un par de decenios, por lo tanto, se trataba solo de sus parientes, que por varias razones decidieron escoger la República Checa como lugar para su domicilio.

\section{Lugares investigados y familias estudiadas}

La determinación del objeto de investigación iba cambiando durante la investigación. Empezamos la investigación en el año 2000 en el asentamiento de Rukonov ${ }^{4} \mathrm{Al}$ principio nuestra intención era realizar una investigación de una localidad, concretamente, de un asentamiento gitano, pero encontramos problemas por el carácter social fragmentado del asentamiento, de hecho, recordamos un número de situaciones en las que nuestra familia de acogida intentó evitar que visitásemos otras familias con las que no tenían relación y dijeron, por ejemplo: «No van», «no están en casa», «es una mala familia, no bebas café allí», etc. Poco a poco, nos dimos cuenta de que, manipulados por nuestra familia de acogida, visitamos más a menudo a sus parientes en otros asentamientos que a sus vecinos en el asentamiento original. Gracias a esta experiencia del campo, entendimos que un asentamiento gitano como una forma definida por el territorio no corresponde a ninguna forma social unida ni a una comunidad local gitana que se supone en general. Por esta razón, abandonamos nuestra intención original y nos dimos cuenta de que, dado que el asentamiento como unidad espacial definida no forma un entero social si no queremos decir una

4 Rukonov (se trata de un pseudónimo de la denominación de la aldea) está situado a unos $15 \mathrm{~km}$ al Oeste de Prešov. Realizamos la investigación sobre el terreno en un asentamiento gitano cercano. Más sobre el tema: Budilová-Jakoubek (2005a). 
«comunidad», era necesario ajustar nuestro tema de investigación y concentrarlo en una unidad de investigación más significativa.

Nuestra unidad de investigación finalmente se define en términos de parentesco y por lazos de afinidad, porque esta unidad, a diferencia del asentamiento, funciona como una unidad social significativa; esta es la unidad de campo que hemos definido.

Nuestros informadores viven en varios asentamientos roma/gitanos eslovacos, incluido el asentamiento de Rukonov, y en varias ciudades checas. Están interconectados por una red compleja e intrincada de parentescos y lazos de afinidad (Budilová, 2006) y se socializan más dentro de este grupo intensivo que fuera de él, definiendo su identidad social primaria como miembros de este grupo de parentesco. El lugar donde viven no es en absoluto importante o relevante para nuestros informadores: la unidad social que estudiamos no corresponde a ningún lugar espacial definido. Lo que cuenta aquí no es el lugar, sino el parentesco. Estudiamos a un grupo de parentesco extenso, pero no localizado. Nuestro grupo de estudio no corresponde a ninguna localidad definida por un terreno; al contrario, funciona como una red no localizada, definida por las relaciones de parentesco entre sus miembros, sin que el lugar de domicilio juegue un papel importante para la percepción de la identidad de sus miembros. A nuestros informadores no les importa dónde están, sino con quién están, ellos mismos dicenः «Si la familia (quiere decir los familiares) está, pues estamos en casa allí». Esta red de parentesco se extiende en dos estados, por lo tanto, los miembros del grupo estudiado no están separados solo por una distancia geográfica, sino también por la frontera sociopolítica entre la República Checa y la República Eslovaca. Este hecho no juega ningún papel en su propia percepción ni en la vida diaria de los informadores. El grupo estudiado no es entonces solo translocal, sino también transnacional.

Cuando hablamos sobre nuestros informadores, a diferencia de cuando hablamos sobre los roma/gitanos en la República Checa por ejemplo, los llamamos gitanos y empleamos este término como traducción del Cigáni usado en eslovaco, que es la manera en la que nuestros informadores se llaman. Es interesante el hecho de que perciben la variante checa de la misma palabra, Cikáni, como peyorativa. Utilizan el término roma para ellos mismos solamente al hablar en romaní, pero como no hablan con nosotros en romaní, sino en eslovaco o checo, utilizamos el término que ellos mismos utilizan como traducción 
para roma, que es Cigáni. La idea habitual de que los roma deciden y actúan como un grupo o una comunidad y eligen a un líder o representante ${ }^{5}$ del grupo, que puede y tiene que hablar en nombre del grupo y decidir por el grupo, se ha revelado como falsa y etnocéntrica. Exactamente, esta falsa idea sobre la existencia de una comunidad local de los roma nos fuerza a buscar en distintos lugares las comunidades de los roma, escribir proyectos para apoyarlas o hacer investigaciones de los asentamientos de los roma. Las consecuencias de la idea mencionada son de carácter teórico-epistemológico y también práctico-político, ya que parcialmente influyen en las conclusiones (que se presuponen de antemano de esta manera) de varias investigaciones que tienen un impacto en las formulaciones de las políticas locales, del Estado y europeas que se refieren a los roma/gitanos.

\section{Familias estudiadas y sus identidades}

Al hablar de los propios modos de identificación de nuestros informadores, tocamos el problema de la identidad o de las identidades. Como ya hemos visto más arriba, nuestros informadores se llaman Cigáni, los gitanos, lo que para ellos no significa pertenecer a ninguna comunidad específica, sino más bien la cualidad específica de ser humanos. Son gitanos, porque son diferentes de los no gitanos, gadžo. ${ }^{6}$ Pero esta diferencia, común con otra, incluso gitanos sin relación, no reúne a toda la gente que se consideran a sí mismos gitanos: no establece semejanzas importantes, solidaridad o aun identidad compartida entre ellos y otros clasificados como roma o gitanos. En este contexto, la distinción de Jenkins de categoría social y grupo parece ser la más apropiada (Jenkins, 1994, 1997). Nuestros informadores son gitanos o roma solo en el nivel de categoría social, categoría que es un agregado de gente definida como tal desde el exterior. Por otra parte, no son ni un grupo de personas que todas se consideran roma o gitanos, ni un grupo de personas con una interacción mutua y sentimiento de pertenencia y se forma desde el interior. Su identidad social primaria y más fuerte en el sentido de sentimiento de pertenencia a un grupo es la identidad

5 La existencia de este tipo de representante solía ser supuesta también en el pasado de una manera tradicional (vajda, čbibalo, mujalo), pero como prueban las investigaciones, se trataba siempre de una representación de parentesco, no la local (Horvátová, 1964: 85) y la persona en cuestión representaba una localidad solo si esta fue habitada por un solo grupo de parentesco.

6 Gadžo es un término utilizado por nuestros informadores para denominar a un no gitano. 
del parentesco que, por supuesto, está conectada con su identidad como gitanos, como se describe anteriormente. El concepto de parentesco es cognaticio aquí: nuestros informadores consideran a cada persona relacionada con ellos por cualquier enlace cognaticio desde la tercera o cuarta generación de un pariente, desde el punto de vista de un ego adulto. Aparte de lazos cognaticios, las relaciones afines son muy importantes; debido a las bodas endogámicas repetidas, las generaciones relacionadas con ego a través de vínculos cognaticios y afines son a menudo las mismas. $\mathrm{O}$, en otras palabras, los parientes están frecuentemente relacionados por una gran variedad de lazos cognaticios y afines (Budilová y Jakoubek, 2004).

Nuestros informadores pertenecen al grupo que se define en términos de parentesco mutuo y lazos afines, nombrados a partir de uno de sus antepasados comunes, Pervalo — un nombre gitano, el Romano nav, que significa 'panzudo'-. Por lo tanto, lo que queremos discutir aquí es la identidad del grupo cuyos miembros se definen ellos mismos como Pervalovci. Este grupo ahora comprende de seis a siete generaciones y, como mencionamos, sus miembros viven en las repúblicas checa y eslovaca. Casi todos los contactos sociales e interacciones de nuestros informadores ocurren dentro de su grupo de parentesco. Los miembros del grupo de parentesco comparten casi todas sus actividades diarias. La parte masculina del grupo trabajan todos juntos, sus miembros celebran banquetes y acontecimientos importantes de la familia juntos y pasan su tiempo libre juntos (Budilová y Jakoubek, 2006). Otro hecho importante es que los miembros de este grupo escogen a su pareja y se casan generalmente dentro de los límites de este grupo según la regla de endogamia.

Esta identidad basada en el parentesco está conectada con la identidad en un nivel más general como la identidad de los gitanos en la medida en que ser gitano significa compartir la importancia de la identidad basada en el parentesco, a su vez compartiendo el esfuerzo de minimizar contactos con los no parientes incluso los gitanos, más exactamente con los gitanos no parientes que se definen siendo parientes. Hemos visto esto al describir los cambios de nuestro tema de investigación: aunque los no parientes vivan puerta con puerta en una unidad espacial definida, no forman ni una unidad social ni cualquier comunidad local. 


\section{Localidad, migración, parentesco e identidad}

De lo que hemos dicho se desprende claramente que algunos de nuestros informadores nacieron en el asentamiento original de Rukonov y han vivido allí toda su vida o se han trasladado a otro asentamiento gitano en Eslovaquia o a una ciudad checa. Otros nacieron en la República Checa o en la parte checa de Checoslovaquia y han vivido en lugares checos o se han movido a Eslovaquia a los asentamientos en los que vivían sus parientes. En muchos casos, estos movimientos no son a largo plazo ni permanentes. De hecho, los lugares donde viven nuestros informadores están cambiando continuamente. Por lo tanto, la identidad definida por el lugar de domicilio, por una aldea, una localidad o una región no está presente generalmente en lo que ellos tienen en cuenta para definir quiénes son. ${ }^{7}$ Ninguno de nuestros informadores ha subrayado nunca cualquier sensación de pertenecer a cierto pueblo, lugar, región o estado importante en su vida.

Ahora vamos a observar más de cerca las oleadas migratorias particulares entre Eslovaquia y la República Checa, que ocurrieron durante los últimos sesenta años, desde el punto de vista del grupo de parentesco que estudiamos para ver cómo estas diversas oleadas migratorias afectaron al grupo de parentesco en sí mismo y al sentimiento de la identidad entre sus miembros y qué impacto tenían las relaciones de parentesco dentro del grupo en su movimiento migratorio.

\section{Primera oleada: desde 1945 hasta los años sesenta del siglo $\mathbf{x} x$}

En este periodo, las primeras personas de la muestra de población estudiada llegaron del asentamiento gitano eslovaco situado cerca de Rukonov, una ciudad pequeña checa de Český Štajnov. ${ }^{8}$ No carece de significación simbólica que

\footnotetext{
7 Para demostrarlo, podemos mencionar nuestra experiencia al pasar con nuestros informadores por el campo en Eslovaquia del Este. Muchas veces pasamos alrededor del castillo de Spišský Hrad, uno de los monumentos más grandes de la Edad Media de Europa central. Nuestros informadores no se dan cuenta de la presencia del castillo, como si su silueta inmensa en el paisaje no existiera. Por otra parte, se orientan muy bien en lo que se refiere a los lugares donde viven sus parientes en la región. Se fijan en la existencia del castillo en el momento en que uno de sus parientes compra el aparcamiento debajo del castillo y empieza a ganar dinero de esta manera. Pasamos entonces por el mismo paisaje, no obstante, cada uno con otro mapa mental. 8 La denominación de la localidad es un pseudónimo.
} 
la primera persona en llegar fuera Adán. Él desempeñó servicios en el ejército en una ciudad de Bohemia septentrional y le fue ofrecido posteriormente un trabajo en una granja colectiva en Český Štajnov. Con la condición de firmar un contrato por veinte años, aquí le ofrecieron una casa. Él llegó con su esposa y dos niños y permaneció en la República Checa para siempre. El establecimiento de Adán en Český Štajnov transcurrió al mismo tiempo que el traslado del hermano menor de Adán, Martin, que llegó con su esposa y sus dos primeros hijos poco tiempo después de Adán. Los otros cinco hijos de Martin nacieron ya aquí. Igual que Adán y en cooperación con él, Martin firmó un contrato similar con la granja colectiva, también consiguió una casa y permaneció allí. Los dos hijos mayores de Martin — los de su primera boda-, encontraron un trabajo en Ústí nad Labem, República Checa, y se casaron y establecieron allí. Una vez la familia nuclear de Martin fue establecida en Český Štajnov, en su casa comenzaron a recibir a un número de parientes no solo de su asentamiento eslovaco original en Rukonov, sino también de otros asentamientos gitanos eslovacos en los que vivían sus parientes. ${ }^{9} \mathrm{Y}$ la migración continuó. Algunos de sus parientes masculinos intentaron encontrar un trabajo en la República Checa, pero vivieron solamente por algún tiempo con Martin y, entonces, la falta de dinero y algunas relaciones extraconyugales que establecieron allí, los obligaron a volver. Sus tentativas de permanecer fracasaron porque no establecieron a sus familias allí. Otros parientes de Adán y de Martin de Rukonov tuvieron más éxito y se establecieron en Ústí nad Labem con sus familias. Más adelante, cuando crecieron, los hijos mayores de Adán llegaron de Český Štajnov y se casaron con los hijos de sus parientes establecidos en Ústí nad Labem.

\section{Segunda oleada: desde los años setenta hasta los años ochenta del siglo $\mathrm{xx}$}

Desde los años setenta tuvieron lugar movimientos de roma/gitanos organizados por el Estado de forma masiva desde Eslovaquia hasta las zonas fronterizas checas. Desde la posguerra, aparte de la familia de Adán y de Martin, solamente otra familia roma/gitana sin relación de otra parte de Eslovaquia vivió en Český Štajnov. En este periodo, otras familias roma/gitanas sin re-

9 Entre estos asentamientos pertenecen, por ejemplo, Vítaz (Dolina), Žehra, Spišské Podhradie, Dobrá Vol'a y otros. 
lación fueron de Eslovaquia a Český Štajnov. El grupo de parentesco gitano que estudiamos no tomó este hecho en consideración, no guardaron ningún contacto social significativo con los miembros de estos grupos ni contrajeron matrimonios con ellos. Desde los años setenta, Adán, Martin y sus parientes se establecieron ya como familias en dos ciudades checas, Český Štajnov y Ústí nad Labem, manteniendo un estrecho contacto entre ellos y con la parte eslovaca de la familia. Varias otras familias relacionadas de Rukonov, de Žehra y de Vítaz aprovecharon para entonces la ayuda financiera del gobierno y se trasladaron desde Eslovaquia a Český Štajnov o a Ústí nad Labem. Eligieron estos lugares porque podrían hacer uso de la ayuda del gobierno y de sus parientes. Entre los lugares checos, Český Štajnov y Ústí nad Labem, donde vivieron los miembros de la muestra estudiada de la población, el intercambio de habitantes continuó. El grupo de parentesco estudiado mantuvo bodas endógamas dentro de sus límites, aunque algunos de sus componentes, por ejemplo, familias nucleares de Český Štajnov, vivieron por entonces durante varias décadas en gran proximidad a otros grupos roma/gitanos sin relación. En este periodo, la migración tomó la forma de modelos establecidos entre diferentes partes o segmentos del mismo grupo de parentesco. Las familias nucleares completas a veces emigraron de cualquier manera, otras veces solo emigraron individuos. En este periodo, la migración apareció por primera vez en la dirección contraria, de la República Checa a Eslovaquia de Rukonov. Una razón frecuente de este tipo de migración era la boda - como mencionamos, el grupo de parentesco era todavía endogámico en ese momento-. Sin embargo, toda la gente que emigraba tenía cierto grado de certeza porque emigraban a lugares en los que ya vivían algunos miembros de su grupo de parentesco.

\section{Tercera oleada: después de 1989}

Las migraciones de los miembros del grupo de parentesco estudiado después de 1989 son diferentes a las anteriores en un aspecto importante. A diferencia de las oleadas migratorias anteriores, cuando a menudo se desplazaban familias nucleares completas, esta última oleada migratoria era insignificante en número: se trató sobre todo de individuos. No obstante, de acuerdo con los movimientos migratorios precedentes, estas migraciones siempre están totalmente en sintonía con las líneas de grupos de parentesco. En este tiempo no 
llegó ningún grupo nuevo que no tuviera relación con los grupos ya establecidos. Las familias nucleares establecidas en ambas repúblicas continuaron con el índice normal de migración entre las localidades checas y las eslovacas. Con frecuencia, especialmente a partir del año 1993, después de la división de Checoslovaquia en dos estados independientes, los motivos para estas migraciones eran generalmente bodas, a veces la «migración» era solamente una cuestión de legalizar una estancia a largo plazo. Después continuó una migración permanente entre ambos estados y entre las localidades dentro de los dos estados, la migración sigue hasta la actualidad.

Un nuevo motivo apareció en este periodo de transición bajo la forma de migración de trabajo. Hasta 1989 no había habido escasez de trabajo, debido a la política comunista de obligatorio y pleno empleo, pero a partir de los años noventa del siglo pasado la situación cambió y la situación económica de los roma/gitanos empeoró, especialmente en las regiones del Este de Eslovaquia. Los miembros eslovacos del grupo de parentesco comenzaron a utilizar sus redes de parentesco para encontrar un trabajo en la República Checa. En este tipo de migración se trata tanto de estancias a corto plazo, denominadas týždňovky ('las semanales') que conciernen los hombres unidos por lazos de parentesco mutuo, como de contratos de trabajo a largo plazo. En este caso, los grupos de trabajo residen en la República Checa durante varias semanas y después siguen, por ejemplo, diez días libres, que suelen pasarlos en su casa en Eslovaquia. Estas formas de migración laboral generalmente no terminan con una estancia a largo plazo ni con un establecimiento permanente en la República Checa. En el periodo después de 1989 no llegó ningún grupo gitano nuevo de parientes a las localidades mencionadas, por ejemplo, a Český Štajnov o a Ústí nad Labem. Todos los parientes ya se habían unido a uno de los grupos o formaban parte de uno de los grupos desde antes.

\section{Conclusiones}

En las páginas precedentes estudiamos a los roma/gitanos desde una perspectiva transnacional. Ya en el prólogo mencionamos que este tipo de esfuerzo no carece de precedentes. A pesar de esto, nuestros resultados no concuerdan con las conclusiones de la mayoría de los estudios dedicados a este tema. La razón principal de la discordancia es la perspectiva elegida y el objeto de interés. Los 
trabajos existentes presentan a los roma/gitanos y su actuación en bloque con el actor correspondiente transnacional, que es en los casos típicos una comunidad roma europea o incluso mundial, eventualmente una diáspora roma; en cambio, nuestro estudio se basó en una microperspectiva en la que elegimos como unidad de estudio un grupo de parentesco roma/gitano concreto. Aunque fuera posible aceptar las perspectivas mencionadas y las conclusiones respectivas como alternativas o complementarias, es necesario añadir que, en el caso de nuestros informadores, la única unidad capaz de tomar una decisión o de actuar, aceptada por los informadores como suya o como «el grupo de nosotros» (Třeštík, 1968: 38), corresponde a una formación de parientes cuya identidad se está construyendo en un plano básico que se forma en oposición a otros grupos roma/gitanos no parientes pero que se determinan desde luego como grupos parientes. A pesar de que nuestros informadores se dan cuenta de que comparten la identidad roma/gitana con cierta categoría de personas, con otros roma/gitanos, lo que ellos mismos consideran como definición de esta categoría es el hecho de compartir el nivel o el código de diferencia, entonces concuerdan en qué consiste el principio de diferenciarse: las oposiciones respectivas siguen una línea de parentesco. A nivel general, podemos decir, de acuerdo con H. Eidheim (Eidheim, 1969), que la dicotomización de los grupos en cuestión es mutuamente complementaria. La existencia de un marco cultural compartido del proceso de dicotomización y de complementación no lleva consigo una existencia de un grupo étnico, por ejemplo, o de una comunidad. En este aspecto es posible considerar nuestro estudio como una crítica de los trabajos mencionados para los que la existencia de este tipo de grupo representa (no solo) un punto de partida conceptual.

Más de la mitad de nuestros informadores nacieron en Checoslovaquia y presenciaron la aparición de los dos estados independientes, de la República Checa y de Eslovaquia. El grupo de parentesco gitano descrito se dividió a lo largo de la frontera entre los dos estados, pero el grupo continuó existiendo sin cambios significativos. Al contrario de lo que cabría esperar, la caída del comunismo, la división de la antigua Checoslovaquia y los cambios sociales y económicos subsiguientes no tuvieron casi ningún efecto sobre el sentimiento de pertenencia en nuestros informadores. Es decir, nuestros informadores, de todas las generaciones e independientemente del idioma, comparten la identi- 
dad del grupo de parentesco que vive en dos estados diferentes y los contactos sociales dentro del grupo no cambiaron.

En la primera oleada de migración, de 1945 a 1960, cuando los primeros migrantes de nuestro grupo llegaron de Eslovaquia a las zonas fronterizas checas, la migración dividió a veces a las familias y fue en algunos casos contra los intereses del grupo de parentesco entero gobernado por el imperativo de que los parientes deben permanecer juntos. No todos los individuos que probaron suerte en la República Checa tuvieron éxito, y solamente los que establecieron a sus familias allí y los que no desbarataron los intereses de la familia o del grupo más amplio de parientes tuvieron éxito a largo plazo. La oleada migratoria subsiguiente era mucho más fácil para las familias nucleares y para los individuos, puesto que tenían la ventaja de los parientes que vivían en lugares checos. Esta oleada en los años setenta y los años ochenta era la más grande y la que tuvo más éxito. El contacto dentro del grupo de parentesco todavía se mantuvo, y el grupo también mantuvo una endogamia estricta aunque no dentro del mismo lugar. La intensidad de la migración en los años noventa no era tan fuerte como la anterior y se limita casi solamente a los individuos referidos. Las bodas endogámicas todavía prevalecían, pero en ambos lugares checos aparecieron las primeras bodas con los miembros de los grupos gitanos sin parentesco del mismo lugar. Lo que es interesante de estas bodas no es el hecho de que ocurrieran, sino que seguían prevaleciendo tan tarde, después de sesenta años de convivencia dentro de una localidad. Hay que subrayar que estas nuevas relaciones entre los grupos gitanos de parentesco mutuamente ajenos hasta ese periodo, que vivían en la misma localidad, no se formaban entre todos los grupos de este tipo, sino que se formaban siempre alianzas escogidas con mucho cuidado. La solidaridad y la frecuencia del contacto entre ambos lugares checos fueron intensificadas. El contacto entre las partes checas y eslovacas del grupo de parentescos fue debilitado en algunos casos, porque algunos de los parientes eslovacos se empobrecieron y perdieron la capacidad de guardar el contacto social rico con los parientes que vivían en lugares lejanos.

Consideremos que las tentativas duraderas del gobierno de crear una identidad checoslovaca, o incluso una nación checoslovaca, ${ }^{10}$ que comenzaron en 1918 con la Checoslovaquia emergente, fueron interrumpidas luego por varios

10 En cuanto a la idea del checoslovaquismo de los principios del siglo xx véase por ej. Pražák 1925 en general y en un contexto Rychlík 1997, 1998. 
años por la Segunda Guerra Mundial, y fueron intensificadas en el estado socialista de la posguerra durante cuatro décadas. La identidad habitual basada en el territorio fue incentivada, entre otros factores, por el apoyo del establecimiento de familias checo-eslovacas mezcladas. Esto se lograba supuestamente, por ejemplo, enviando a muchachos jóvenes de la República Checa para su servicio militar a Eslovaquia y viceversa, bajo la presunción de que encontrarían esposas allí. Este esfuerzo nunca tuvo éxito, como los demógrafos señalan a menudo, dado el porcentaje bajo de bodas mixtas de checos y eslovacos. Con la división de las dos repúblicas, oficialmente de la República Federal Checa y Eslovaca, en 1993, se abandonaron y olvidaron estos esfuerzos. Sin embargo, hay grupos que no estaban, quizá intencionalmente, afectados por estas intervenciones de Estado a largo plazo. Uno de ellos es el grupo que acabamos de describir. Ni la identidad basada en el lugar ni en el estado era, ni es, importante para ellos; su mundo se caracteriza por la tensión fuerte de la identidad del parentesco. La formación de su grupo de parentesco checoslovaco fue retrasada, y terminó solo después de la división de Checoslovaquia. Sin embargo, pueden ser vistos, tomando en consideración el nivel de contacto social (inter) estatal o transnacional dentro del cual funciona, o fue forzado a funcionar, el grupo de parentesco, como cierta clase de los últimos checoslovacos ${ }^{11}$ del pasado.

11 Usando esta expresión relativamente metafórica no queremos de ninguna manera poner en duda la identidad checoslovaca que profesan muchos ciudadanos de la antigua Checoslovaquia hasta la actualidad y habitualmente con cierta nostalgia. Al contrario, los miembros del grupo observado no se sienten como checoslovacos ni a nivel de la identidad ni se declaran ellos mismos así. No obstante, lo que vemos como fundamental y lo que quisimos demostrar en este artículo es que en oposición a los sentimientos, a las declaraciones o a los programas políticos del checoslovaquismo, los miembros del grupo realmente actúan y existen como checoslovacos al nivel de las prácticas diarias. 


\section{Bibliografía}

Armstrong, J. A. (1976), «Mobilized and Proletarian Diasporas», The American Political Science Review, 70 (2), 393-408.

Bell, C. \& Newby, H. (1973), Community Studies. An Introduction to the Sociology of the Local Community, London, George Allen and Unwin.

Brandes, D. (2001), Der Weg zur Vertreibung 1938-1945. Pläne und Entscheidungen zum "Transfer" der Deutschen aus der Tschechoslowakei und aus Polen, München, Oldenbourg.

BoŘKovcovÁ, M. (2004), «Romský etnolekt češtiny» [El etnolecto roma de la lengua checa], in Ja коu век, M. \& Hirt, T. (eds.), Romové - kulturologické etudy [The Roma - culturological studies], Plzeň, Čeněk, 292-308.

Budilová, L. (2006), «Cigánská př́buzenská skupina: antropologická perspektiva» [Un grupo de parentesco gitano: una perspectiva antropológica], in Mareš, P. \& Hofírek, O. (eds.), Sociální reprodukce a integrace: ideály a meze [Las reproducciones sociales y la integración: los ideales y los limites], Brno, Masarykova univerzita, 203-224.

Budilová, L. \& Jakoubek, M. (2006), «Dva životy / Duj dživipena» [Dos vidas / Duj dživipena], in Lenk, L.; Svoboda, M.; Jakoubek, M.; Kučerová, K. (eds.), Argonauti za obzorem západu. Sbornik textů z 1. mezinárodní konference AntropoWebu, Plzeň 4. - 5. 11. 2005. [Los argonautas detrás del horizonte del Oeste. Las Actas de la Conferencia de AntropoWeb de Plzen organizada del 4 al 5 de noviembre de 2005], Plzeň, Nakladatelství a vydavatelství Vlasty Králové, 96-106.

Budilové, L. \& Jакоuвeк, M. (2006), «Kinship, social organization and genealogical manipulations in Gypsy "osadas" in Eastern Slovakia», Romani Studies 5, 16 (1), 63-82.

Budilová, L. \& Jакоuвек, M. (2005a), «Historicko-etnografický náčrt romské osady u obce Rukonov» [Esbozo histórico y etnográfico de una población de los roma en las cercanías de la aldea de Rukonov], Lidé mésta 1/2005 (14), 75-100.

Budilová, L. \& Jakoubek, M. (2005b), «Ritual impurity and kinship in Gypsy osada in Eastern Slovakia», Romani Studies 5, 15 (1), 1-29.

Budilová, L. \& Jакоивек, M. (2004), «Př́buzenství v romské osadě» [The kinship in a Roma settlement], in Jakoubek, M. \& Hirt, T. (eds.) Romové - 
kulturologické etudy [The Roma - culturological studies], Plzeň, Nakladatelství Čeněk, 9-64.

Crow, G. \& Allan, G. (1994), Community life. An Introduction to Local Social Relations, New York, Harvester-Wheatsheaf.

Davidová, E. (2000), «Poválečný vývoj a osudy Romů v letech 1945-1989» [El desarrollo en la época de posguerra y los destinos de los roma en los años 1945-1989], in Černobílý život [La vida en blanco y negro], Praha, Gallery. 67-78.

Eidheim, H. (1969), "When ethnic identity is a social stigma», in BARTH F. (eds.) Ethnic Groups and Boundaries: The Social Organization of Culture Difference, Oslo, Universitetsforlaget, 39-57.

Haišman, T. (1999), «Romové v Československu v letech 1945-1967. Vývoj institucionálního zájmu a jeho dopady» [Los roma en Checoslovaquia en los años 1945-1967. El desarrollo del interés institucional y sus consecuencias], in Romové v České republice (1945-1998) [Los roma en la República Checa (1954-1998)], Praha, Socioklub, 137-183.

Hanzal, J. (2004), Cikáni na Moravě v 15. až 18. století. Dějiny etnika na okraji společnosti [Los gitanos en Moravia en los siglos XV-XVIII. La bistoria de un étnico en el margen de la sociedad], Praha, Nakladatelství Lidové noviny.

HirT, T. (2004), «Romská etnická komunita jako politický projekt; kritická reflexe» [Una comunidad étnica roma como un proyecto político - una reflexión crítica], in Jакоивек, M. \& Нirт, T. (eds.), Romové - kulturologické etudy [The Roma - culturological studies], Plzeň, Nakladatelství Čeněk, 72 91.

Horvát hová, E. (1964), Cigáni na Slovensku [Los gitanos en Eslovaquia], Bratislava, Vydavatel'stvo Slovenskej akadémie vied.

Horváthová, J. (2002), Kapitoly $z$ dějin Romů [Los capítulos de la bistoria de los roma], Praha, Společnost Člověk v tísni, společnost při ČT, o.p.s. v nakladatelství Lidové noviny.

Hü bschmannová, M. (ed.) (2006), Po Židoch Cigáni. Svèdectví Romů ze Slovenska 1939-1945. I. dil (1939 - srpen 1944) [Después de los judios los gitanos. El testimonio de los roma de Eslovaquia 1939-1945. Tomo I (1939agosto de 1944)], Praha, Triáda.

Jakoubeк, M. (2004), Romové: konec (ne)jednoho mýtu, Praha, Socioklub. 
Jakoubek, M. \& Hirt, T. (eds.) (2004), Romové: kulturologické etudy. Etnopolitika, príbuzenství a sociální organizace [Los roma: los estudios culturológicos. Etnopolitica, parentesco y organización social], Plzeň, Vydavatelství a nakladatelství Aleš Čeněk.

Jenkins, R. (1994), «Rethinking Ethnicity: Identity, Categorization and Power», Ethnic and Racial Studies, 17 (2), 197-223.

Jenkins, J. (1997), Rethinking Ethnicity. Arguments and Explorations, London, Sage.

KRIŠTOF, R. (2003), Závěrečná zpráva k projektu Analýza soudobé migrace a usazováni přislušnikư romských komunit ze Slovenské republiky na územi České republiky (č.j. OAMP-948/2003) [El informe final del proyecto Análisis de la migración contemporánea y el establecimiento de los miembros de las comunidades roma de la República Eslovaca en el territorio de la República Checa], Praha. IOM Mezinárodní organizace pro migraci. [En línea] Disponible en: <http://aa.ecn.cz/img_upload/ea85d6c87301f0a7507b0e8d7b873b63/ analyza_migrace_rom.pdf $>$ [Consulta: 18 de mayo de 2014].

LípA, J. (1965), Cikánština $v$ jazykovém prostředi slovenském a českém: $k$ otázkám starých a novějšich složek v její gramatice a lexiku [La lengua gitana en el ambiente lingüistico eslovaco y checo: las cuestiones de los rasgos antiguos $y$ nuevos en su gramática y léxico], Praha, ČSAV.

Lípa, J. (1990), The Fate of Gypsies in Czechoslovakia under Nazi domination, in Berenbaum, M. (ed.), A Mosaic of Victims: Non-Jews Persecuted and Murdered by the Nazis, New York-London, 207-215.

Mann, A., B. (2001), Romský dějepis [Historia de los roma], Praha, Fortuna.

NeČAs, C. (1981), Nad osudem českých a slovenských Cikánů v letech 1939-1945 [Sobre el destino de los gitanos checos y eslovacos en los años 1939-1945], Brno. Univerzita J.E. Purkyně v Brně.

NeČAs, C. (1999), Romové v České republice věera a dnes [Los roma en la República Checa ayer y hoy en día], Olomouc, Univerzita Palackého.

Nečas, C. (2000), The Holocaust of the Czech Roma, Praha, Prostor.

Nosková, H. \& Váchová, J. (2000), Reemigrace Čechů a Slováki z Jugoslávie, Rumunska a Bulharska (1945-1954) [La reemigración de los checos y de los eslovacos de Yugoslavia, Rumania y Bulgaria (1945-1954)], Praha. Ústav pro soudobé dějiny AVČR. 
PAPE, M. (1997), A nikdo vám nebude věrit: Dokument o koncentračním táboře Lety u Písku [Y nadie os creerá: Documentación sobre el campo de concentración de Lety u Písku], Praha, Nakladatelství G plus G.

Pavelčínová, N. (2004), Romové v českých zemích v letech 1945-1989 [Los roma en los países checos en los años 1945-1989], Praha, Úřad dokumentace a vyšetřování zločinů komunismu.

Pogány, I. (2008), «Přijímání ustavující se národní identity: Romové střední a východní Evropy» [La aceptación de la identidad nacional surgente: los roma de la Europa central y oriental], in Jакоивек, M. (ed.) Etnicita a Cikáni [La etnicidad y los gitanos], Praha, Triton.

PražÁk, A. (1925), Československý národ [La nación checoslovaca], Bratislava, Academia.

Rychlík, J. (1997), Češi a Slováci ve 20. století. Česko-slovenské vztahy 19141945 [Los checos y los eslovacos en el siglo XX. Las relaciones checo-eslovacas 1914-1945], Bratislava, Academic Electronic Press.

Rychlík, J. (1998), Češi a Slováci ve 20. století. Česko-slovenské vztahy 1945 1992 [Los checos y los eslovacos en el siglo XX. Las relaciones checo-eslovacas 1945-1992], Bratislava, Academic Electronic Press.

Safran, W. (1991), «Diasporas in Modern Societies: Myths of Homeland and Return», Diaspora, 1, 83-99.

Sheffer, G. (1995), «The Emergence of New Ethno-National Diasporas», Migration, 28, 5-28.

StAněK, T. (1991), Odsun Němců z Československa 1945-1947 [El desalojo de los alemanes de Checoslovaquia 1945-1947], Praha, Academia - Naše vojsko.

Stojka, P. \& Pivoň, R. (2003), Náš život/Amáro trajo [Nuestra vida/Amáro trajo], Bratislava, SD studio.

Šiklová, J. (2002), Romové a Charta 77 [Los roma y la Carta 77], [en línea] Disponible en: <http://romove.radio.cz/cz/clanek/18211> [Consulta: 18 de mayo de 2014].

TŘešTík, D. (1968), «Věk zlatý a železný» [La Edad de Oro y del Hierro], in Graus, F. (ed.) Naše živá a mrtvá minulost, 8 esejí o českých dějinách [Nuestro pasado vivo y muerto, 8 ensayos sobre la historia checa], Praha, Svoboda. 26-43. 
VACulík, J. (1984), «K reemigraci a usídlování volyňských Čechů v letech 1945-1947» [Sobre la reemigración y el establecimiento de los Checos de Volyne en los años 1945-1947], Český lid, 71 (3), 167-177.

VACulík, J. (1993), Reemigrace zahraničnich Čechio a Slováků v letech 1945 1950 [La reemigración de los Checos y Eslovacos extranjeros en los años 19451950], Brno, UTGM.

VAn BaAR, H. (2008), «The Way out of Amnesia? Europeanization and the Recognition of the Roma's Past and Present. Third Text», Critical Perspectives on Contemporary Art and Culture, 22 (3), 373-385.

Vagačová, I. \& FotтA M. (2006), Rómovia a drubá svetová vojna. Čítanka [Los roma y la Segunda Guerra Mundial. Libro de lectura], Bratislava, Nadácia Milana Šimečku. 